\title{
sciendo
}

\section{Maximum Oxygen Uptake of Male Soccer Players According to their Competitive Level, Playing Position and Age Group: Implication from a Network Meta-Analysis}

\author{
by \\ Maamer Slimani ${ }^{1}$,Hela Znazen ${ }^{1,2}$, Bianca Miarka33, Nicola Luigi Bragazzi ${ }^{4,5}$
}

The aim of the present meta-analysis was to compare the maximum oxygen uptake (VO2max) characteristics of male soccer players relative to their competitive level, playing position and age group and the interaction between them. The meta-analysis was based on 16 studies, employing 2385 soccer players aged 10-39 years. Higher-level soccer players showed greater ( $E S=0.58$ [95\% CI 0.08-1.08], $S E=0.25$, var $=0.06, z=2.29, p=0.022$ ) VO2max performance with respect to their lower level counterparts. Furthermore, lower VO2max values in goalkeepers than defenders $(E S=1.31$ (SE 0.46) [95\% CI 0.41-2.21], var $=0.21, z=2.84, p=0.004)$ and midfielders $(E S=1.37(S E 0.41)[95 \%$ CI 0.58 to 2.17], var $=0.16, z=3.40, p=0.001$ ) were found. Thus, VO2max increased significantly with age (all, $p<0.01)$ : Under 10 versus Under 11 years, Under 11 versus Under 12 years, Under 12 versus Under 13 years, Under 13 versus Under 14 years, Under 14 versus Under 15 years and Under 16-18 versus Under 20-23 years. VO2max performance is the most powerful discriminator between higher and lower-level soccer players. These findings indicate also the need for sports scientists and conditioning professionals to take the VO2max performance of soccer players into account when designing individualized position specific training programs.

Key words: aerobic performance, age, position, soccer.

\section{Introduction}

Soccer is one of the most popular team sports practiced around the world. During the season, elite male soccer players practice on a daily basis, often twice a day, play one or two matches per week, and take part in international tournaments such as World Championships and the Olympic Games (Slimani and Nikolaidis, 2017; Slimani et al., 2018; Stølen et al., 2005). This heavy schedule of practices and games requires well developed physical, mental and physiological characteristics (Slimani et al., 2016).

Cardiovascular fitness is one of the most important aspects of physical fitness in soccer ( $\mathrm{Da}$ Silva et al., 2008; Nikolaidis, 2011; Stølen et al., 2005). In this context, well-developed aerobic fitness helps soccer players to maintain repetitive high-intensity actions within a soccer match, to accelerate the recovery process, and to maintain their physical condition at an optimum level during the entire game and season (Stølen et al., 2005).

In the extant scholarly literature, previous reviews dealing with physiological attributes and correlates of soccer players have been published

\footnotetext{
1 - Research Laboratory "Sport Performance Optimization", National Centre of Medicine and Science in Sport (CNMSS), El Menzah, Tunisia.

2 - Department of Physical Education and Sport- Faculty of Education, Taif University, Saudi Arabia.

3 - Physical Education and Sports School, Federal University of Rio de Janeiro, Brazil.

4 - School of Public Health, Department of Health Sciences (DISSAL), Genoa University, Genoa, Italy

5 - Department of Neuroscience, Rehabilitation, Ophthalmology, Genetics, Maternal and Child Health (DINOGMI), Section of Psychiatry, Genoa University, Genoa, Italy.
} 
(Da Silva et al., 2008; Stølen et al., 2005). However, these reviews detailed only physiological demands of Brazilian soccer players and without providing detailed information about the difference between competitive levels, playing positions and age categories. Since the last review (Stølen et al., 2005), more than 10 studies investigating the physiological profile, particularly aerobic performance, of soccer players according to many factors, have been published, underscoring the importance of this topic. Thus, the authors of this paper take the opportunity to re-evaluate the evidence to date. It is well known that understanding the specific requirements of soccer players of different competitive levels, playing positions and age categories can provide insightful information regarding what is truly needed for competitive success in that sport and prepare them for higher playing levels later in their career (Nikolaidis et al., 2014, 2015).

Despite the existing studies investigating the aerobic performance relative to different competitive levels, playing positions and age groups, the interaction between the above mentioned factors (competitive levels $\times$ playing positions $\times$ age groups) remains inconclusive. Furthermore, no meta-analysis review has been conducted so far. Identification of positional differences between competitive levels and age groups can be achieved with the use of metaanalysis: a method that allows to overcome the problems of small sample size and low statistical power. Meta-analysis is a quantitative approach in which individual study findings addressing a common problem are statistically integrated and analyzed (Hedges and Olkin, 1985). Since metaanalysis can effectively increase the overall sample size, it also can provide a more precise estimate of the age and playing position that requires a high level of aerobic performance. Thus, the purpose of this meta-analysis was to establish the physiological profile, particularly maximum oxygen uptake $\left(\mathrm{VO}_{2 \max }\right)$, of male soccer players according to their competitive level, playing position and age group, and to examine the interaction between them.

\section{Methods}

A meta-analysis was conducted to verify whether $\mathrm{VO}_{2 \max }$ measures distinguished between soccer players of different competitive levels, playing positions and age groups. Relevant studies were combined and analyzed to provide an overview of the available research on this topic. Conclusions were based on the included studies with suggestions for practical applications for strength and conditioning professionals as well as future investigations.

Search Strategy

The present meta-analysis was conducted according to the Preferred Reporting Items for Systematic Reviews and Meta-analysis (PRISMA) guidelines (Moher et al., 2009). The reviewed articles were selected following an extensive search process of the English language literature, including major databases such as PubMed/MEDLINE, Google Scholar, Web of Science and Scopus databases, with the dates ranging from January 1, 1995 to May 31, 2017. Search terms included: soccer, physical and physiological features, maximum oxygen uptake, $\mathrm{VO}_{2 m a x}$, age, playing positions, and experience level.

Inclusion and Exclusion Criteria

The inclusion criteria followed the ones of the Population/Intervention/Comparison/ Outcome(s) (PICO) framework:

(a) Population: Studies recruiting male soccer players at any age category and competitive level as participants.

(b) Intervention: Original investigations focusing on aerobic performance $\left(\mathrm{VO}_{2 \max }\right)$, as assessed using different methods (Laboratory tests: Treadmill test, Maximal Bruce Treadmill test, Cycloergometer; Field tests:20-m progressive run test, $20 \mathrm{~m}$ multistage shuttle run test, continuous progressive track run test, 1,000-m run/walk test) and at any period of the season (off-season (before the season), preseason (the beginning of the season, preseason), competitive season (in-season, precompetitive period, the beginning of the competitive season, competitive season), and end of the season) of male soccer players.

(c) Comparison: $\mathrm{VO}_{2 \max }$ of male soccer players relative to their competitive level, playing position, and/or age group.

(d) Outcome(s): $\mathrm{VO}_{2 \max }$ value.

The exclusion criteria were as follows:

(a) Reviews, comments, opinions, and commentaries, interviews, letters to the editor, editorials, as well as gray literature (posters, conference 
abstracts, book chapters, and books) were excluded; available reviews were scanned for increasing the chance of including potentially relevant articles.

(b) No comparison of $\mathrm{VO}_{2 m a x}$ between soccer players of different competitive levels, playing positions, and/or age groups.

(c) Lacking quantitative information and details.

\section{Screening Strategy}

The studies were independently screened by two authors looking at study titles and abstracts for potential eligibility. Screening questions had been developed and pilot tested with a subset of records before implementation. Disagreement was assessed using $\kappa$ statistics and resolved through discussion until consensus was reached.

\section{Quality Appraisal}

Two reviewers conducted methodological quality assessment on each included article using the modified Downs and Black scale (Downs and Black, 1998), which is appropriate for nonrandomized control trials (NRCTs) and casecontrol study designs. Twenty seven items were used to determine the Methodological Quality Checklist of each study. Twenty-six 'yes'-or-'no' questions were scored totaling up to 26 possible points. In this review, the questions were categorized under 4 sections: Reporting (10 items), External validity (3 items), Study bias (7 items), and Confounding and selection bias (6 items).

Statistical Analyses

For the meta-analysis part, data were extracted from the included studies using a standardized documentation form. The variables extracted included the surname of the first author, year of publication, sample size, age, competitive level and playing position of players. Effect estimates were computed as standardized mean differences, with their $95 \%$ confidence interval (CIs). Meta-analyses were carried out using the commercial software Comprehensive MetaAnalysis (CMA v3.0). While the concept of multiplicity of statistical testing and, as such, the need for correcting and adjusting generated $p$ values for multiple comparisons have been widely recognized and addressed in primary research, these issues have been overlooked in research synthesis and meta-research. Some scholars think, indeed, that meta-analyses, relying upon effect sizes and not on $p$-values, and pooling together a relevant number of studies, are not plagued by the increased probability of falsely rejecting a true null hypothesis. Instead, "although research synthesis may combine findings from hundreds of studies and thousands of respondents, they are not immune to inflated type 1 error when many statistical tests are conducted without adequate control for the error rate" (Bender et al., 2008; Cook and Campbell, 1979). Currently, there is still no consensus regarding the best way to address this issue. In the current paper, we performed a univariate meta-regression (a multi-variate regression was not possible because of the number of included studies and moderators under scrutiny), to study the overall effect and after we performed standard direct pairwise comparisons, adjusting the $p$-value for multiple testing. Statistical heterogeneity was also assessed in our metaanalysis, using the $\mathrm{I}^{2}$ statistic. If $\mathrm{I}^{2}$ was $>50 \%$, this was regarded as substantial significant heterogeneity. Possible publication bias was visually inspected with a funnel plot, looking at asymmetry of the graph, as well as computing the Egger's regression test.

When available, standard direct/head-tohead pairwise comparisons were synthesized. Indirect comparisons were estimated via the formula of Bucher and colleagues (1997).

\section{Results}

\section{Study Selection}

The search strategies yielded a preliminary pool of 1521 possible papers. The full text of 35 articles was retrieved and assessed for eligibility against the inclusion criteria. After a careful review of their full text, 18 articles were excluded and the remaining 17 articles were eligible for inclusion in the review. Particularly, 4 papers assessed $\mathrm{VO}_{2 \max }$ of soccer players according to the competitive level. Eight articles focused on $\mathrm{VO}_{2 \max }$ of soccer players relative to their playing position. Nine studies focused on $\mathrm{VO}_{2 \max }$ of soccer players relative to age groups.

Subjects

The total number of participants included in this review was 2385. Sample size ranged between 27 and 296. The subject's age within the selected studies ranged from 10 to 39 years. Additionally, the training status of participants 
varied from amateur to elite.

Methodological Quality

The methodological quality scores ranged from 8 to 15 , with the average score being around 11.

\section{Random-effect Model}

Due to the statistically significant heterogeneity found, a random-effect model was applied in the current paper. $\mathrm{VO}_{2 \max }$ values stratified according to competitive levels, playing positions and age groups, $\mathrm{I}^{2}$ resulted $93.05 \%$, $96.70 \%$, and $97.77 \%$, respectively.

Competitive levels

Greater $\mathrm{VO}_{2 \max }$ values in higher-level soccer players than in lower-level players were observed $(\mathrm{ES}=0.58$ [95\% CI 0.08-1.08], $\mathrm{SE}=0.25$, variance $=0.06, \mathrm{z}=2.29, p=0.022$; Figure 1 ).
Statistically significant predictors were found to be the performed test $(p=0.0076)$ and the period of the season ( $p=0.0056$; with values higher at off-season and lower at the end of the season, $p=0.0051$ and $p$ $=0.0449$, respectively). Age was not found to significantly impact $\mathrm{VO}_{2}$ max stratified according to competitive levels $(p=0.7792)$. No evidence of publication bias could be found, both performing the Egger's regression test and visually inspecting the funnel plot.

\begin{tabular}{lr} 
Study name & $\begin{array}{r}\text { Std diff } \\
\text { in means }\end{array}$ \\
& \multicolumn{1}{l}{$\begin{array}{l}\text { S } \\
\text { Reilly et al. (2000) }\end{array}$} \\
Arnason et al. (2004) & 2.320 \\
Gil et al. (2007a)a & 3.278 \\
Gil et al. (2007a)b & 0.424 \\
Gil et al. (2007a)c & -1.088 \\
Gil et al. (2007a)d & 2.058 \\
le Gall et al. (2010)a & 0.489 \\
le Gall et al. (2010)b & 0.384 \\
le Gall et al. (2010)c & -0.450 \\
le Gall et al. (2010)d & 0.145 \\
le Gall et al. (2010)e & -0.061 \\
le Gall et al. (2010)f & 0.143 \\
le Gall et al. (2010)g & 0.356 \\
le Gall et al. (2010)h & 0.534 \\
le Gall et al. (2010)i & -0.678 \\
& 0.582
\end{tabular}

Statistics for each study

error
0.391
0.212
0.446
0.297
0.364
0.349
0.274
0.277
0.277
0.171
0.178
0.178
0.285
0.288
0.290
0.254

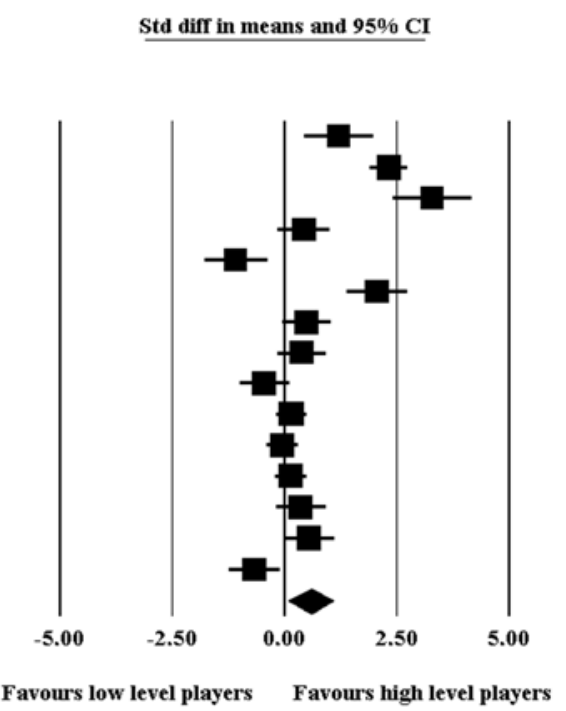

Figure 1

Forest plot of differences in $\mathrm{VO}_{2 \max }$ values stratified according to competitive levels (higher-versus lower-level). 


\begin{tabular}{lrrrrrrrr} 
Study name & \multicolumn{7}{c}{ Statistics for each study } \\
\cline { 5 - 8 } & $\begin{array}{c}\text { Std diff } \\
\text { in means }\end{array}$ & $\begin{array}{c}\text { Standard } \\
\text { error }\end{array}$ & $\begin{array}{c}\text { Variance } \\
\text { Lower } \\
\text { limit }\end{array}$ & $\begin{array}{r}\text { Upper } \\
\text { limit }\end{array}$ & Z-Value & p-Value \\
Arnason et al. (2004) & 1.238 & 0.293 & 0.086 & 0.664 & 1.812 & 4.229 & 0.000 \\
Tahara et al. (2006) & 1.335 & 0.472 & 0.223 & 0.409 & 2.260 & 2.826 & 0.005 \\
Silvestre et al. (2006) & 1.354 & 0.657 & 0.432 & 0.067 & 2.642 & 2.061 & 0.039 \\
Gil et al. (2007b) & 1.020 & 0.229 & 0.052 & 0.571 & 1.468 & 4.456 & 0.000 \\
Aziz et al. (2008) & 0.987 & 0.309 & 0.095 & 0.381 & 1.592 & 3.195 & 0.001 \\
Wong et al. (2009) & -0.257 & 0.389 & 0.151 & -1.019 & 0.505 & -0.661 & 0.508 \\
Sporis et al. (2009) & 4.583 & 0.376 & 0.141 & 3.846 & 5.320 & 12.192 & 0.000 \\
Portes et al. (2015) & 0.296 & 0.228 & 0.052 & -0.151 & 0.742 & 1.298 & 0.194 \\
& 1.309 & 0.460 & 0.212 & 0.407 & 2.211 & 2.844 & 0.004
\end{tabular}

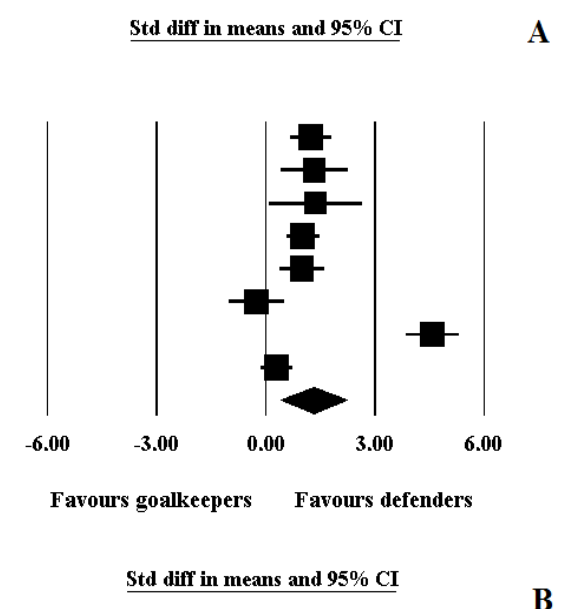

\begin{tabular}{|c|c|c|c|c|c|c|c|}
\hline \multirow[t]{2}{*}{$\underline{\text { Study name }}$} & \multicolumn{7}{|c|}{ Statistics for each study } \\
\hline & $\begin{array}{l}\text { Std diff } \\
\text { in means }\end{array}$ & $\begin{array}{l}\text { Standard } \\
\text { error }\end{array}$ & Variance & $\begin{array}{c}\text { Lower } \\
\text { limit }\end{array}$ & $\begin{array}{c}\text { Upper } \\
\text { limit }\end{array}$ & Z-Value & p-Value \\
\hline Tahara et al. (2006) & -0.451 & 0.343 & 0.118 & -1.124 & 0.222 & -1.313 & 0.189 \\
\hline Gil et al. $(2007 \mathrm{~b})$ & 0.384 & 0.177 & 0.031 & 0.036 & 0.731 & 2.165 & 0.030 \\
\hline Aziz et al. (2008) & 0.270 & 0.274 & 0.075 & -0.266 & 0.807 & 0.987 & 0.324 \\
\hline Arnason et al. (2004) & 0.021 & 0.181 & 0.033 & -0.334 & 0.376 & 0.115 & 0.909 \\
\hline Sporis et al. (2009) & -0.164 & 0.158 & 0.025 & -0.475 & 0.146 & -1.038 & 0.299 \\
\hline Silvestre et al. (2006) & -0.828 & 0.622 & 0.387 & -2.048 & 0.392 & -1.330 & 0.184 \\
\hline Portes et al. (2015) & -0.219 & 0.160 & 0.026 & -0.533 & 0.095 & -1.367 & 0.172 \\
\hline Wong et al. (2009) & 0.544 & 0.348 & 0.121 & -0.138 & 1.225 & 1.564 & 0.118 \\
\hline & 0.009 & 0.119 & 0.014 & -0.224 & 0.242 & 0.074 & 0.941 \\
\hline
\end{tabular}

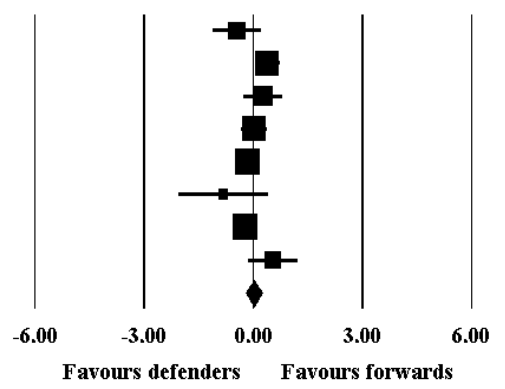

Study name

$\underline{\text { Statistics for each study }}$

$\begin{array}{rc}\begin{array}{c}\text { Std diff } \\ \text { in means }\end{array} & \begin{array}{c}\text { Standard } \\ \text { error }\end{array} \\ 0.046 & 0.157 \\ 0.130 & 0.275 \\ 0.102 & 0.460 \\ -0.087 & 0.160 \\ 0.306 & 0.220 \\ 0.795 & 0.311 \\ 1.273 & 0.173 \\ 0.000 & 0.148 \\ 0.321 & 0.190\end{array}$

Lower Upper

Variance limit limit Z-Value p-Value

$\begin{array}{lllll}0.025 & -0.262 & 0.354 & 0.293 & 0.770\end{array}$

$\begin{array}{lllll}0.076 & -0.410 & 0.670 & 0.473 & 0.636\end{array}$

$\begin{array}{lllll}0.211 & -0.799 & 1.003 & 0.221 & 0.825\end{array}$

$\begin{array}{lllll}0.026 & -0.401 & 0.227 & -0.540 & 0.589\end{array}$

$\begin{array}{lllll}0.048 & -0.125 & 0.736 & 1.393 & 0.164\end{array}$

$\begin{array}{lllll}0.097 & 0.185 & 1.406 & 2.552 & 0.011\end{array}$

$\begin{array}{lllll}0.030 & 0.933 & 1.613 & 7.342 & 0.000\end{array}$

$\begin{array}{lllll}0.022 & -0.290 & 0.290 & 0.000 & 1.000\end{array}$

Sporis et al. (2009)

0.091

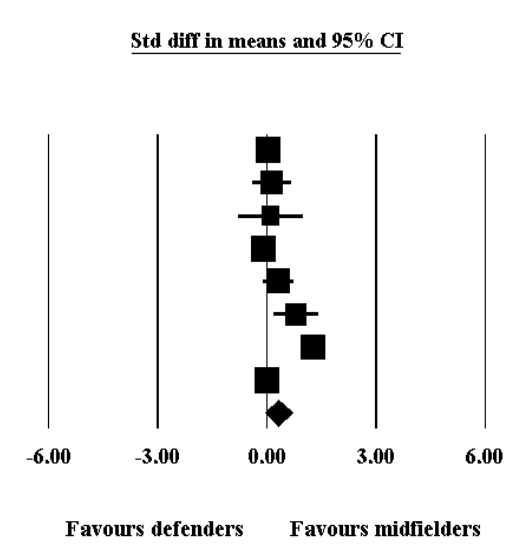

C

Figure 2a.

Forest plot of differences in $\mathrm{VO}_{2 \max }$ values stratified according to playing positions

(defenders versus goalkeepers [A]; forwards versus defenders [B]; defenders versus midfielders [C]). 


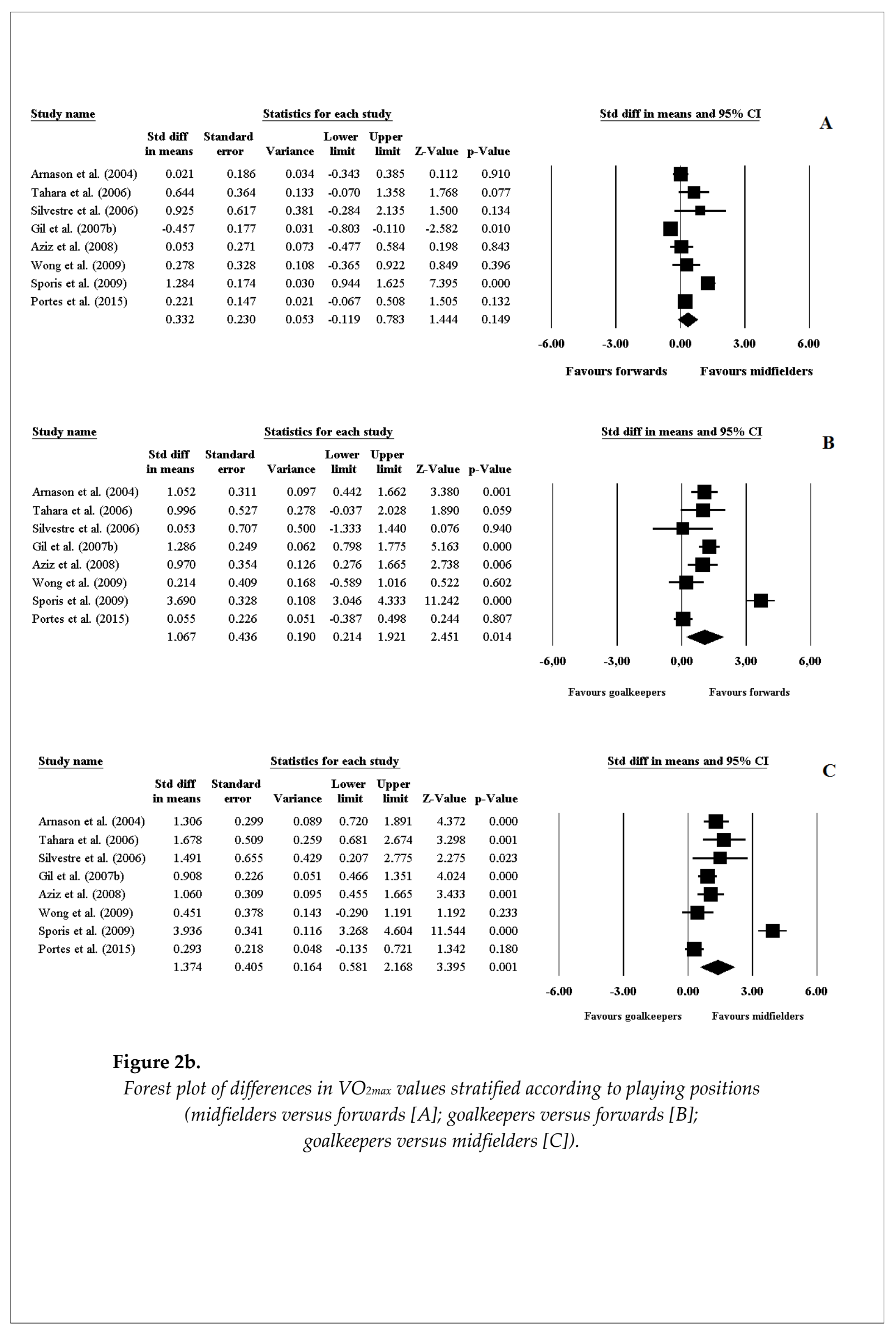




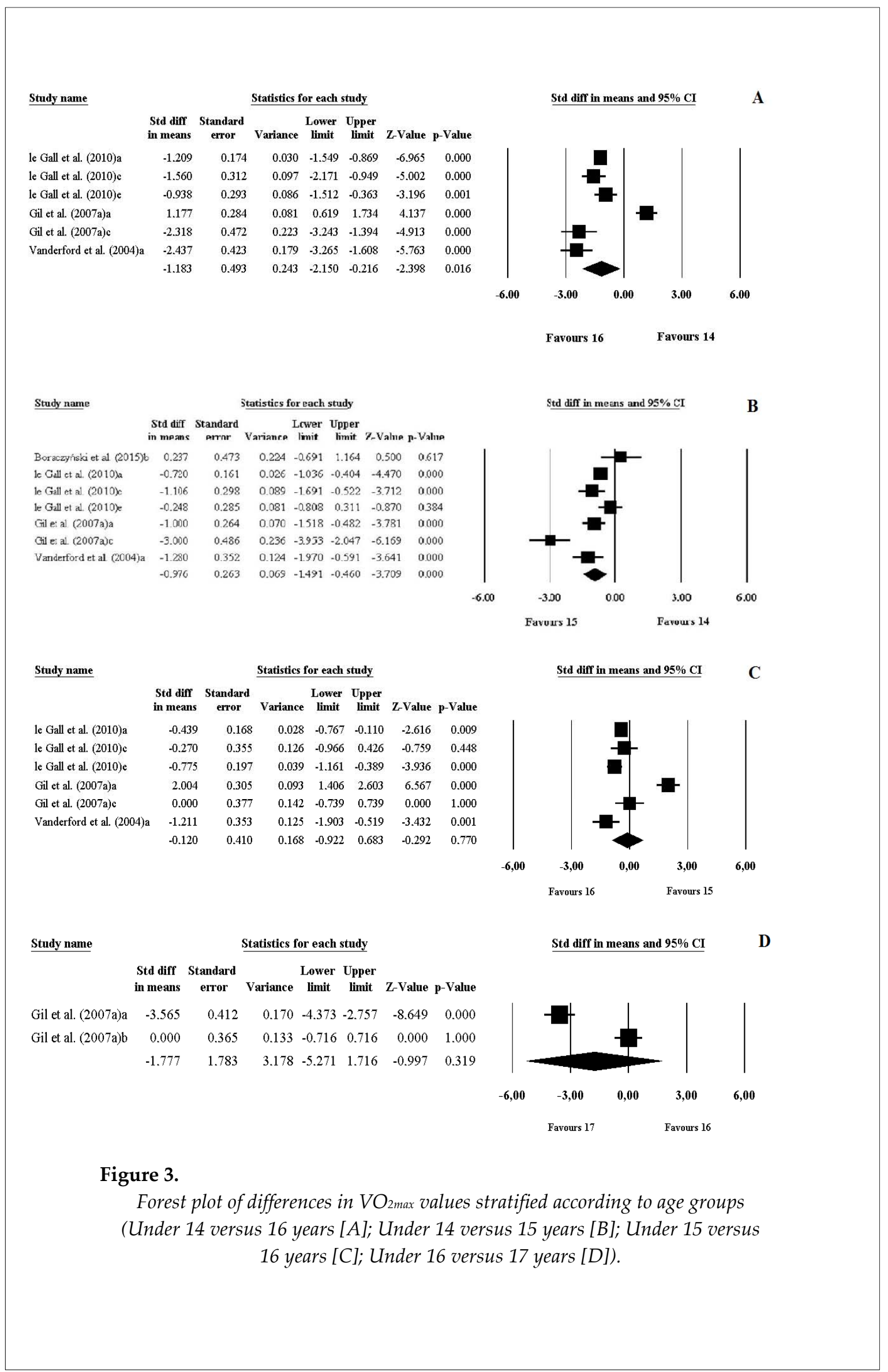




\section{Playing positions}

Overall, the competitive level $(p=0.0564)$ and period of season $(p=0.0537)$ did not significantly impact $\mathrm{VO}_{2 \max }$ values stratified according to playing positions, as well as the performed test $(p=0.5179)$ and age $(p=0.8792)$. No evidence of publication bias could be found. Focusing on pairwise comparisons, the difference in $\mathrm{VO}_{2 \max }$ values between midfielders versus forwards ( $\mathrm{ES}=0.33$ (SE 0.23) [95\% CI -0.12 to 0.78], var $=0.05, \mathrm{z}=1.44, p=0.149)$, as well as the difference between midfielders versus defenders (ES $=0.32$ (SE 0.19) [95\% CI -0.05 to 0.69], var $=0.04$, $\mathrm{z}=1.69, p=0.091)$ was not significant. Greater $\mathrm{VO}_{2 \max }$ values in midfielders than in goalkeepers ( $\mathrm{ES}=1.37$ (SE 0.41) [95\% CI 0.58 to 2.17], $\operatorname{var}=0.16, \mathrm{z}=3.40, p=0.001$ ) were observed, whereas the difference between forwards versus defenders ( $E S=0.01$ (SE 0.12) [95\% CI -0.22 to 0.24], var $=0.01, z=0.07, p=0.941)$ did not yield statistical significance. Finally, higher $\mathrm{VO}_{2 \max }$ values in forwards ( $\mathrm{ES}=1.07$ (SE 0.44) [95\% CI 0.21-1.92], var $=0.19, \mathrm{z}=2.45, p=0.014)$ and in defenders $(\mathrm{ES}=1.31$ (SE 0.46) [95\% CI 0.41-2.21], $\operatorname{var}=0.21, \mathrm{z}=2.84, p=$ 0.004 ) than in goalkeepers was detected. Concerning pairwise comparisons, no evidence of publication bias was found apart from defenders versus goalkeepers (Figures 2a, 2b).

Age Groups

$\mathrm{VO}_{2 \max }$ increased significantly with age. At the meta-regression, period of the season $(p=$ 0.0003; with higher values during the competitive season with respect to the pre-season, $p=0.0112$, and to the end of the season, $p=0.0001$ ), and the competitive level $(p=0.0002)$ were found to be statistically significant predictors of $\mathrm{VO}_{2 \max }$ values stratified according to age. No evidence of publication bias could be found, both visually inspecting the funnel plot and performing the Egger's regression test.

Concerning pairwise comparisons, higher $\mathrm{VO}_{2 \max }$ values in U14 than in U15 (ES $=-0.98$ (SE 0.26 ) [95\% CI -1.49 to -0.46$]$, $\operatorname{var}=0.07, \mathrm{z}=-3.71, p<$ 0.001 ), and in U14 than in U16 (ES $=-1.18$ (SE 0.49) [ $95 \%$ CI -2.15 to -0.22 ], $\operatorname{var}=0.24, \mathrm{z}=-2.40, p=0.016$ ) were found. The difference between U15 versus U16 group, instead, failed to achieve statistical significance (ES $=-0.12$ (SE 0.41) $[95 \%$ CI -0.92 to $0.68]$, $\operatorname{var}=0.17, \mathrm{z}=-0.29, p=0.770)$. Similarly, the difference between U16 versus U17 was not significant (ES $=-1.78$ (SE 1.78) $[95 \%$ CI -5.27 to
$1.72], \operatorname{var}=3.18, z=-1.00, p=0.319)$. For further details, the reader is referred to Figure 3 . Concerning pairwise comparisons, no evidence of publication bias was found.

Other pairwise comparisons were estimated via indirect comparisons according to the equation of Bucher and colleagues (1997). Age 14 versus age 17 yielded an ES of 0.59 [95\% CI -3.03 to 4.22$]$, whereas age 15 versus age 17 an ES of 1.66 [ $95 \%$ CI -1.93 to 5.25$]$.

\section{Discussion}

The present meta-analysis shows that aerobic fitness was a discriminator of successful performance in soccer between higher- and lowerlevel players. It was also shown that the outfield players, except for forwards, exhibited the highest $\mathrm{VO}_{2 \max }$ values in the team. Thus, $\mathrm{VO}_{2 \max }$ increased significantly with age, particularly comparing the groups each year, between Under 10 and 15 years. Furthermore, the competitive level, positional and age differences varied by the period of the season.

Determining $\mathrm{VO}_{2 \max }$ of soccer players according to the competitive level, playing position, and age group is useful when assessing talent, in selection of players, the design of physical conditioning programs, predicting and monitoring physical match performance. Therefore, establishing reference variables in high performance players can assist in making important informed decisions, particularly for the strength and conditioning staff at soccer clubs to optimize the training program.

Competitive Level

Overall, $\mathrm{VO}_{2 \max }$ values were in the range of $48-62 \mathrm{ml} / \mathrm{kg} / \mathrm{min}$ for male soccer players regardless of their competitive level. Particularly, $\mathrm{VO}_{2 \max }$ values reported range from 59.2 to $63.2 \mathrm{ml} / \mathrm{kg} / \mathrm{min}$, from 59.2 to 61.5 , from 58.2 to 62.2 and from 57.8 to $61.7 \mathrm{ml} / \mathrm{kg} / \mathrm{min}$ for elite, international, profesional and amateur male soccer players, respectively, in different competitive levels and age groups.Furthermore, the present meta-analysis reported that $\mathrm{VO}_{2 m a x}$ largely distinguished higherfrom lower-level soccer players. Particularly, significantly greater $\mathrm{VO}_{2 \max }$ values were reported in three investigations, all of which stratified by the competition level. Specifically, Reilly et al. (2000) and Arnason et al. (2004) reported that $\mathrm{VO}_{2 \max }$ was significantly greater amongst elite soccer players when compared with sub-elite ones. In agreement 
with the high $\mathrm{VO}_{2 \max }$ values in superior competitors, significantly greater $\mathrm{VO}_{2 \max }$ values were reported in selected soccer players when compared with non-selected counterparts (Gil et al., 2007a). In contrast, when comparing within competition levels, le Gall et al. (2010) reported that $\mathrm{VO}_{2 \max }$ was not a discriminator of successful performance in soccer at the age of 14, 15 and 16 years. Furthermore, the competitive level differences varied by the period of the season and the assessment method of $\mathrm{VO}_{2 \max }$.

In conclusion, aerobic performance is an important variable for achieving high-level soccer performance and accurately discriminates between higher- and lower-level soccer players. For that reason, practitioners should plan specific training sessions soliciting the aerobic system in amateur soccer players, in order to simultaneously improve the recovery pattern and performances as in elite players, with respect to the period of the season and the performed test.

\section{Playing Positions}

Identifying each player's specialized position is especially important in order to optimize their physical development so that to prepare them for higher playing levels later in their career. Particularly, the current meta-analysis found significant differences in $\mathrm{VO}_{2 \max }$ between playing positions. More specifically, higher $\mathrm{VO}_{2 \max }$ values in outfield players, except for forwards, than in goalkeepers were reported. Overall $\mathrm{VO}_{2 \max }$ values reported in the scientific literature varied between 48.4 and $57.5 \mathrm{ml} \cdot \mathrm{kg}^{-1} \cdot \mathrm{min}^{-1}$ for male goalkeepers, between 53.2 and $62.8 \mathrm{ml} \cdot \mathrm{kg}^{-1} \cdot \mathrm{min}^{-1}$ for defenders, between 54.7 and $63 \mathrm{ml} \cdot \mathrm{kg}^{-1} \cdot \mathrm{min}^{-1}$ for midfielders, and between 54.5 and $62.9 \mathrm{ml} \cdot \mathrm{kg}^{-1} \cdot \mathrm{min}^{-}$ ${ }^{1}$ for forwards. A possible reason for this is that each playing position has different tactical requirements and that goalkeepers cover the least distance while midfielders run the greatest distances during soccer match-play (Mohr et al., 2003; Rampinini et al., 2007). $\mathrm{VO}_{2 \max }$ values of each playing position may also reflect training effects from the match-play in competition as well as in training, in addition to the organized conditioning performed by these players. In addition, the present meta-analyses showed that the competitive level, period of the season, performed test, and participants' age did not significantly impact $\mathrm{VO}_{2 \max }$ values stratified according to playing positions. A previous systematic review reported that non-professional forwards had higher mean $\mathrm{VO}_{2 \max }$ values compared with nonprofessional young midfielders and defenders, but when the players approached the professional level, positional differences also existed, with higher $\mathrm{VO}_{2 \max }$ values in elite young midfielders compared with elite attackers and defenders (Slimani and Nikolaidis, 2017). It seems that positional differences appear at all ages. Finally, practitioners should adopt an appropriate training plan considering playing positions of players that would adequately elicit heightened cardiorespiratory demands in outfield players, except for forwards, at all ages compared to goalkeepers.

Age Groups

It was shown that $\mathrm{VO}_{2 \max }$ increased with age, particularly between Under 10 and Under 14 years (Boraczyński et al., 2015; Canhadas et al., 2010), Under 14 and Under 15 years and between Under 14 and Under 16 years. Higher $\mathrm{VO}_{2 \max }$ values in senior than in junior soccer players were also observed (Aziz et al., 2008). This is explained in part by the differences of biological maturity status, body size and training volume between Under 10 and Under 15 years and between senior and junior soccer players (Mendez-Villanueva et al., 2010). One possible reason for heterogeneity between studies in young soccer players is that the variety of tests to exhaustion that have been used in male soccer studies to predict $\mathrm{VO}_{2 \max }$ may influence the comparison between the results of non-professional young athletes who presented greater heterogeneity in the mean values of $\mathrm{VO}_{2 \max }$. Moreover, $\mathrm{VO}_{2 \max }$ measurements may be not reliable in patients as well as in unmotivated or exercise tests-naïve subjects, who may stop exercising before reaching $\mathrm{VO}_{2 \max }$ (Poole et al., 2017). On the other hand, for young elite or professional players, $\mathrm{VO}_{2 \max }$ means were more homogeneous and the comparisons between different ages showed a larger effect size, indicating a stronger effect. Thus, $\mathrm{VO}_{2 \max }$ exercise tests in young healthy athletes can be performed until exhaustion. For instance, while running or cycling, the incremental cardiopulmonary exercise test yields a highly reproducible $\mathrm{VO}_{2 \max }$ irrespective of the exercise test protocol, work rate, forcing function or pacing strategy (Poole et al., 2017). In addition, there were no significant differences between Under 15 and Under 16, 
between Under 16 and Under 17, between youth (14 years) and senior (24 years) players (Chamari et al., 2005), between pubescent (13.4 years) and postpubescent (17 years) players (Cunha et al., 2011) and between 18.6, 22.5, and 26.7 year old players (Botek et al., 2016). This phenomenon could be explained by the small difference in chronological and biological age between those groups. Finally, soccer players should be at different maturation levels, and those who are more mature are likely to present greater aerobic performance (Carling et al., 2009; Hirose et al., 2009; Lovell et al., 2015). These differences in $\mathrm{VO}_{2 \max }$ across ages indicate that highintensity training may be administered in older soccer players' training programs, with respect to their competitive level and the period of the season.

\section{Period of the Season}

The competitive soccer season lasts from eight to nine months, with a mean of two matches a week and a high aerobic intensity demand estimated at about $\sim 80 \%$ of $\mathrm{VO}_{2 \max }$ by game(Reilly et al., 2000). This intensity is similar to the anaerobic threshold values of professional players (Edwards et al., 2003), what makes it difficult to keep optimal physical fitness throughout the entire season. This statement is supported by present findings which indicated that the period of the season significantly impacted $\mathrm{VO}_{2 \max }$ values stratified according to competitive levels and age groups. Coaches and strength and conditioning specialists should determine the differences in $\mathrm{VO}_{2 \max }$ performance between competitive levels and age groups at the off-season and competitive season rather than at the end of the season and the pre-season.

Assessment Method Effect

Regarding the evaluation of $\mathrm{VO}_{2 \max }$, studies demonstrated a special attention to fieldtest assessment, about $60 \%$ of all of them proposed continuous and intermittent shuttle running fieldtests (Aziz et al., 2008; Boraczyński et al., 2015; Canhadas et al., 2010; Gil et al., 2007a, b; Le Gall et al., 2010; Portes et al., 2015; Reilly et al., 2000; Silvestre et al., 2006) for their ecological, criterion and synchronized validity and subsequently a very strong $(r=0.8-1.0)$ relationship with the direct assessment method for senior athletes (Bangsbo et al., 2008; Castagna et al., 2009; Leger and Lambert, 1982; Paliczka et al., 1987; Rampinini et al., 2007). Present meta-analyses highlighted that the type of a test significantly impacted $\mathrm{VO}_{2 \max }$ values stratified according to competitive levels and age groups. This result indicated an important confounding factor, since the measurement method could influence $\mathrm{VO}_{2 \max }$ results.

Limitation and Practical Implications

Present results could not provide insights into the interactions between the reported factors as our meta-analysis is based on a variety of studies using different combinations of factors (e.g., competitive levels, playing positions, age groups, period of the season, and performed tests). Previous studies did not consider these specific factors, most of investigations verified only the influence of one or two independent factors. In addition, previous studies had very heterogeneous sample sizes, what makes our meta-regression analysis essential, demonstrating the effect size and considering the samples.

The ability of the cardiorespiratory system to transport oxygen to the muscles refers to the central component of $\mathrm{VO}_{2 \max }$ - the most physiologically important and, therefore, the most frequent measured variable in the assessment of male soccer players. To insure valid and reliable $\mathrm{VO}_{2 m a x}$, present findings indicated practical concerns according to the competitive level, playing position and age groups. Results allow us to suggest that maturational and training effects on oxygen delivery (via pulmonary diffusion, cardiac output, and blood volume and flow) should be considered in training programs, as higher effect sizes of age and level comparisons were demonstrated in meta-regression analysis. Results showed that the outfield players, except for forwards, exhibited higher $\mathrm{VO}_{2 \max }$ values, while goalkeepers showed the lowest values of $\mathrm{VO}_{2 \max }$. These findings seems to suggest that each player's position needs to consider specific muscle mass and the motion used for soccer' training programs, since the potential sites for $\mathrm{VO}_{2 \max }$ limitation in the peripheral component include mitochondrial enzyme (facilitating the ATP production) levels, muscle diffusion capacity and capillary density (Bassett and Howley 2000). Moreover, $\mathrm{VO}_{2 \max }$ variables can be used to design specific training programs for particular playing positions.

\section{Conclusions}

Despite the strengths given by its systematic approach, the current meta-analysis is 
characterized by a number of shortcomings that should be properly recognized. High, statistically significant heterogeneity is the major limitation, calling for caution in interpreting the findings. Furthermore, evidence of publication biases was noticed. The lack of consistency or uniformity in testing protocols to assess $\mathrm{VO}_{2 \max }$, variety in the fitness status of players, the stage of the season when they were tested, their motivation and environmental conditions make it difficult to compare between studies and only assumptions should be made when assessing these differences. In regard to the above-mentioned limitations, the present meta-analysis is essential to characterize and create a more detailed profile of soccer players' aerobic fitness in their different competitive levels, playing positions and age groups.
Among trained soccer players, the $\mathrm{VO}_{2 \max }$ test was able to discriminate between goalkeepers and outfielders, except for forwards, which suggests that aerobic performance is one of the most important indicators of talent in soccer. This finding emphasizes outfield-position specific fitness training. Superior aerobic performance was also associated with a higher level of competitiveness and/or adaptation to highintensity training and this has implications for the teams' training strategies. Practitioners should adopt an appropriate training plan that would adequately stress the cardiorespiratory system in soccer players, with respect to their age, competitive level and period of the season.

\section{References}

Arnason A, Sigurdsson SB, Gudmundsson A, Holme I, Engebretsen L, Bahr R. Physical fitness, injuries, and team performance in soccer. Med Sci Sports Exerc, 2004; 36: 278-285

Aziz AR, Mukherjee S, Chia MY, Teh KC. Validity of the running repeated sprint ability test among playing positions and level of competitiveness in trained soccer players. Int J Sports Med, 2008; 29: 833-838

Bangsbo J, Iaia FM, Krustrup P. The Yo-Yo intermittent recovery test: a useful tool for evaluation of physical performance in intermittent sports. Sports Med, 2008; 38: 37-51

Bassett DR Jr, Howley ET. Limiting factors for maximum oxygen uptake and determinants of endurance performance. Med Sci Sport Exer, 2000; 32(1): 70-84

Bender R, Bunce C, Clarke M, Gates S, Lange S, Pace NL, Thorlund K. Attention should be given to multiplicity issues in systematic reviews. J Clin Epidemiol, 2008; 61: 857-865

Boraczyński M, Boraczyński T, Podstawski R, Wójcik Z. Relationships between anthropometric traits, body composition and aerobic capacity in male soccer players aged 13-15 years. J Kinesiology Exer Sci, 2015; 69(25): 33-40

Botek M, Krejčí J, McKune AJ, Klimešová I. Somatic, endurance performance and heart rate variability profiles of professional soccer players grouped according to age.J Hum Kinet, 2016; 54(1): 65-74

Bucher HC, Guyatt GH, Griffith LE, Walter SD. The results of direct and indirect treatment comparisons in meta-analysis of randomized controlled trials. J Clin Epidemiol, 1997; 50: 683-691

Canhadas IL, Silva RLP, Chaves CR, Portes LA. Anthropometric and physical fitness characteristics of young male soccer players. Rev Bras Cineantropom Desempenho Hum, 2010; 12: 239

Carling C, le Gall F, Reilly T, Williams AM. Do anthropometric and fitness characteristics vary according to birth date distribution in elite youth academy soccer players? Scand J Med Sci Sports, 2009; 19(1): 3-9

Castagna C, Impellizzeri F, Cecchini E, Rampinini E, Alvarez JC. Effects of intermittent-endurance fitness on match performance in young male soccer players. J Strength Cond Res, 2009; 23: 1954-1959

Chamari K, Moussa-Chamari I, Boussaidi L, Hachana Y, Kaouech F, Wisløff U. Appropriate interpretation of aerobic capacity: Allometric scaling in adult and young soccer players. Br J Sports Med, 2005; 39(2): 97101

Cook TD, Campbell DT. Quasi-experimentation: Design \& analysis issues for field settings. New York, NY: Rand McNally: 1979 
Cunha G, Lorenzi T, Sapata K, Lopes AL, Gaya AC, Oliveira A. Effect of biological maturation on maximal oxygen uptake and ventilatory thresholds in soccer players: An allometric approach. J Sports Sci, 2011; 29(10): 1029-1039

Da Silva CD, Bloomfield J, Marins JC. A review of stature, body mass and maximal oxygen uptake profiles of U17, U20 and first division players in Brazilian soccer. J Sports Sci Med, 2008; 1;7(3): 309-19

Downs SH, Black N. The feasibility of creating a checklist for the assessment of the methodological quality both of randomised and non-randomised studies of health care interventions. J Epidemiol Community Health, 1998; 52(6): 377-84

Edwards AM, Clark NA, Macfadyen AM. Lactate and ventilatory thresholds reflect the training status of professional soccer players where maximal aerobic power is unchanged. J Sports Sci Med, 2003; 1: 23-29

Gil S, Ruiz F, Irazusta A, Gil J, Irazusta J. Selection of young soccer players in terms of anthropometric and physiological factors. J Sports Med Phys Fit, 2007a; 47: 25-32

Gil SM, Gil, Ruiz F, Irazusta A, Irazusta J. Physiological and anthropometric characteristics of young soccer players according to their playing position: relevance for the selection process. J Strength Cond Res, 2007b; 21: 438-45

Hedges LV, Olkin I. Statistical Methods for Meta-Analysis. New York: Academic Press, 1985

Hirose N. Relationships among birth-month distribution, skeletal age and anthropometric characteristics in adolescent elite soccer players. J Sports Sci, 2009; 27(11): 1159-66

le Gall F, Carling C, Williams M, Reilly T. Anthropometric and fitness characteristics of international, professional and amateur male graduate soccer players from an elite youth academy. J Sci Med Sport, 2010; 13: 90-95

Leger L, Lambert J. A maximal multistage 20 m shuttle run test to predict VO2max. Eur J Appl Physiol, 1982; 49: 1-12

Lovell R, Towlson C, Parkin G, Portas M, Vaeyens R, Cobley S. Soccer player characteristics in English lowerleague development programmes: the relationships between relative age, maturation, anthropometry and physical fitness. PLoS One, 2015; 10(9): e0137238

Mendez-Villanueva A, Buchheit M, Kuitunen S, Poon TK, Simpson B, Peltola E. Is the relationship between sprinting and maximal aerobic speeds in young soccer players affected by maturation? Pediatr Exerc Sci, 2010; 22(4): 497-510

Moher D, Liberati A, Tetzlaff J, Altman DG. Preferred reporting items for systematic reviews and meta-analyses: The prisma statement. Ann Intern Med, 2009; 151: 264-269

Mohr M, Krustrup P, Bangsbo J. Match performance of high-standard soccer players with special reference to development of fatigue. J Sports Sci, 2003; 21: 519-528

Nikolaidis PT. Cardiorespiratory power across adolescence in male soccer players. Hum Physiol, 2011; 37(5): 636-41

Nikolaidis PT, Ziv G, Arnon M, Lidor R. Physical characteristics and physiological attributes of football goalkeepers - the importance of individual data. J Hum Sport Exerc, 2015; 10(2): 602-614

Nikolaidis PT, Ziv G, Lidor R, Arnon M. Intra-individual variability in soccer players of different age groups playing different positions. J Hum Kinet, 2014; 40: 1-13

Paliczka VJ, Nichols AK, Boreham CAG. A multistage shuttle run as a predictor of running performance in maximal oxygen uptake in adults. Br J Sports Med, 1987; 21: 163-65

Poole DC, Jones AM. Measurement of the maximum oxygen uptake $\mathrm{VO}_{2 m a x}$ : $\mathrm{VO}_{2 \text { peak }}$ is no longer acceptable. J Appl Physiol, 2017; 122(4): 997-1002

Portes LA, Canhadas IL, RLP Silva, de Oliveira NC. Anthropometry and fitness of young elite soccer players by field position. Sport Sci Health, 2015; 11: 321-328

Rampinini E, Coutts AJ, Castagna C, Sassi R, Impellizzeri FM. Variation in top level soccer match performance. Int J Sports Med, 2007; 28: 1018-1024

Rampinini E, Bishop D, Marcora SM, Bravo DF, Sassi R, Impellizzeri FM. Validity of simple field tests as indicators of match-related physical performance in top-level professional soccer players. Int J Sports Med, 2007; 8: 228-235 
Reilly T, Williams AM, Nevill A, Franks A. A multidisciplinary approach to talent identification in soccer. J Sport Sci, 2000; 18: 695-702

Silvestre R, West C, Maresh CM, Kraemer WJ. Body composition and physical performance in men's soccer: a study of a National Collegiate Athletic Association Division I team. J Strength Cond Res, 2006; 20(1): 177183

Slimani M, Nikolaidis PT. Anthropometric and physiological characteristics of male Soccer players according to their competitive level, playing position and age group: a systematic review. J Sports Med Phys Fitness, 2017; doi: 10.23736/S0022-4707.17.07950-6. [Epub ahead of print]

Slimani M, Znazen H, Hammami A, Bragazzi NL. Comparison of body fat percentage of male soccer players of different competitive levels, playing positions and age groups: a meta-analysis. J Sports Med Phys Fitness, 2018; 58(6): 857-866

Slimani M, Bragazzi NL, Tod D, Dellal A, Hue O, Cheour F, Taylor L, Chamari K. Do cognitive training strategies improve motor and positive psychological skills development in soccer players? Insights from a systematic review. J Sports Sci, 2016; 34(24): 2338-2349

Sporis G, Jukic I, Ostojic SM, Milanovic D. Fitness profiling in soccer: physical and physiologic characteristics of elite players. J Strength Cond Res, 2009; 23(7): 1947-1953

Stølen T, Chamari K, Castagna C, Wisløff U. Physiology of soccer. Sports Med, 2005; 35(6): 501-536

Tahara Y, Moji K, Tsunawake N, Fukuda R, Nakayama M, Nakagaichi M, Komine T, Kusano Y, Aoyagi K. Physique, body composition and maximum oxygen consumption of selected soccer players of Kunimi High School, Nagasaki, Japan. J Physiol Anthropol, 2006; 25: 291-297

Vanderford LM, Meyers MC, Skelly WA, Stewart CC, Hamilton KL. Physiological and sport-specific skill response of Olympic youth soccer athletes. J Strength Cond Res, 2004; 18(2): 334-342

Wong PL, Chamari K, Dellal, A, Wisløff U. Relationship between anthropometric and physiological characteristics in youth soccer players. J Strength Cond Res, 2009; 23(4): 1204-1210

\section{Corresponding author:}

\section{Maamer Slimani}

Research Laboratory - Sport Performance Optimisation, National Centre of Medicine and Science in Sport (CNMSS), El Menzah, Tunisia

Phone: +21697067695

Email: maamer2011@hotmail.fr 